\title{
Using workshops as a tool to deliver interprofessional learning
}

\author{
Helena Low ${ }^{1}$ and Judy Stone ${ }^{2}$
}

Summary: Workshops are used widely as a tool in both education and industry for brainstorming, problem solving, sharing knowledge, skills and raising awareness of issues. In this international initiative, workshops were chosen as the educational delivery tool for interprofessional learning (IPL) due to their flexible, interactive and collaborative nature. In 2009, Australia and New Zealand were developing the experience and expertise required to facilitate IPL effectively with diverse groups of participants with differing needs. An international collaborative connection was fostered with the UK Centre for the Advancement of Interprofessional Education (CAIPE) to access expertise already existing in the UK. This expertise was combined with the developing facilitation skills within Australasia in a series of ten workshops. Over three hundred health and social care practitioners, educators, policy makers and planners participated. The tour was neither funded nor designed as a formal research study. After the tour, feedback was received from institutions and participants on the impact of the tour as a whole and of individual workshops. This feedback indicated that the workshops had acted as a catalyst and impetus for further interprofessional learning and development and collaboration in practice. They had been effective in delivering interprofessional learning.

Keywords: workshops; interprofessional education; interprofessional learning; interactive learning; practice learning; reflection

1.Vice Chair: Centre for the Advancement of Interprofessional Education (CAIPE)

2. Interprofessional Learning Coordinator. ACT Health, Canberra, Australia

Address for Correspondence: Helena Low, CAIPE, c/o Higher Education Academy, c/o King's College, 150 Stamford Street, London, SE1 9NH. peter_helenalow@hotmail.com.judy.stone@act.gov.au

Date of publication: 1st November 2010

Acknowledgements: The authors of this article thank Dawn Forman who cofacilitated these workshops, the workshop hosts, organisers and participants for their warmth and hospitality, and particularly ACT Health for supporting this series of workshops

26 J. of Practice Teaching \& Learning 9(3) 2009, pp.26-46. DOI: 10.1921/ 146066910X541629. @ w\&b 


\section{Introduction}

In 2008, the Australian Capital Territory (ACT) Health, the public health service provider for the ACT, commissioned two IPL workshops for practising health professionals (Low \& Stone, 2008). Anecdotal feedback indicated that this international collaborative initiative had resulted in the transfer of knowledge and facilitation skills, the initiation of several quality improvement projects and improved networking and communication pathways amongst participants. Interest was expressed by academics and health workers in other areas for similar workshops. ACT Health agreed to organise and support a follow-up tour for universities and their associated health and social care practitioners. The link with CAIPE having already been established, a series of ten workshops was planned and delivered to self selecting universities and health departments across Australia and New Zealand during a four week period in February and March 2009.

\section{Context}

Over the last decade Australia and New Zealand have undergone similar processes of modernization and change in health and social care services as elsewhere in the world, (Meads \& Ashcroft, et al., 2005). Both countries focused on workforce development and reforms in service delivery prompted in Australia by the Productivity Commission's Issues Paper on Australia's Health Workforce (2005); the Council of Australian Governments; National Partnership Agreement on Hospital and Health Workforce Reform (2008); and in New Zealand, by the New Zealand Health Workforce Advisory Committee report (2003) and the New Zealand Workforce Taskforce (2008). At the same time the Australian higher education system was also undergoing reform (DEEWR 2008) with an emphasis on the need to consider education and training issues on an integrated rather than profession-by-profession basis. These government initiatives increased interest in, and raised the profile of, interprofessional education (IPE) as a means of preparing health and social care professions to work more collaboratively, and thereby improve the safety and quality of care for patients, clients and

27 J. of Practice Teaching \& Learning 9(3) 2009, pp.26-46. DOI: 10.1921/ 146066910X541629. @ wE-b 
consumers of health and welfare services. IPL is increasingly seen as a vehicle for developing a more responsive and flexible workforce with the capacity to work across professional, organisational and agency boundaries (Barr et al., 2005).

\section{Workshops and interprofessional learning}

IPE occurs 'when two or more professions learn with, from and about each other to improve collaboration and the quality of care' (CAIPE, 2002). This definition emphasises the need for explicit interprofessional interaction between participants. Reeves et al, (2007) argue that this form of interaction within IPE promotes development of the competencies required for effective collaboration and that planners of IPE should use appropriate educational strategies such as those set out by Barr, 2005, pp. 97-102). These include, exchange-based, problemfocused, and simulation-based learning as well as electronic learning (e-learning) methods. To maximize opportunities for interaction, several learning activities are typically used within IPE programs

IPL embraces the principles of adult learning, is client focused, practice led and seeks to improve services (Stone, 2009). Howkins and Bray (2008, p. xviii) describe IPL as 'a process in which different professionals learn from each other through interaction to develop collaborative practice. This may be in a formal education setting or opportunistically in the workplace'. It is an active and interactive learning process between different professions.

Workshops are suited to the delivery of IPL as they place emphasis on problem solving, experiential and interactive learning and require the engagement of all participants. They provide brief sessions of intensive teaching and learning which emphasise an exchange of information, knowledge and perspectives between participants. Participants are respected as adult learners and an effort is made to offer authentic, contextualised learning opportunities in a safe learning environment (Clay et al., 1999). Workshops which use these active, interactive learning strategies encourage dialogue and an exchange of information and opinions; they offer opportunities for reflection and creativity in problem solving. Studies have shown that students in a classroom setting using active learning techniques can learn more than those in

28 J. of Practice Teaching \& Learning 9(3) 2009, pp.26-46. DOI: 10.1921/ 146066910X541629. ( ) wEb 
a traditional lecture format (Pool et al., 2009). Singh et al, (1998) found that short, interactive, problem-oriented, workshop-based learning was as effective in changing attitudes as much longer attachments using traditional teaching. Fronek et al., (2009) also highlighted that participants value the use of scenarios and the discussion of these with professionals from a range of backgrounds in a safe environment; as well as sharing experiences and the focus on service and practice.

Soubhi et al., (2009) describe how professionals face the daily challenges of interprofessional practice at the front lines, where the complexity of care varies, information is fragmentary and ill defined problems most encountered. 'Through formal and informal interactions with colleagues, professionals engage in renewed conversations about their practice, build their knowledge about how things work, and adjust their practices accordingly' (Soubhi et al., 2009, p.53). Workshops can provide an opportunity for this kind of interaction in a safe environment where learning can be optimised.

\section{The workshop aims}

The overarching, general aims of the IPL workshops were to: raise awareness and increase understanding of IPE and IPL; develop local facilitation of IPL skills; stimulate IPL and collaborative practice initiatives and to promote IPL networks both nationally and internationally. Specific aims and objectives for each workshop were derived from the stated requirements of the host institution and the individual participants, received in advance of the event.

\section{Preparation and planning for the workshops}

The role of the interprofessional facilitator is regarded as pivotal (Reeves et al., 2007). As well as having a good understanding of group learning theories, facilitators need practical skills, experience, and confidence to meet the differing demands of interprofessional groups (Holland et a.1, 2002). Low (1998) reported that facilitators of IPL should have the ability to discern and address a range of complex issues, such as different professional cultures, perceived power and status of different

29 J. of Practice Teaching \& Learning 9(3) 2009, pp.26-46. DOI: 10.1921/ 146066910X541629. ( $w \&$ b 
professions and professional language, as well as have the sensitivity required to work across professional and organisational barriers to achieve change. Also, that a good understanding of the context in which IPE is taking place is required - the government, national and local agenda in relation to health and social care policy, the professional and education agendas.

General planning started a year before the workshop tour and intensified at six months. The way in which IPE is developed and delivered is dependent on the local context, influenced by local resources, issues and stakeholders. A clear understanding of institutional and individual expectations was also needed. Howkins \& Bray (2008) highlight the importance of understanding the learning situation as fully as possible in advance of IPL episodes and stressed the need to invest time in pre planning with all stakeholders. They identified principles for IPL facilitators which also included the need to invest time in group development. This meant:

knowledge of the diversity within the group, different perspectives, different educational backgrounds and expectations, and the extent to which people within the group know each other and have had an opportunity to develop an understanding of each others' roles; and understanding the power and hierarchical relationships in more complex groups. (Howkins \& Bray, 2008, p.23)

Information was gathered through the use of three forms developed and used by CAIPE over a number of years and e-mailed to host institutions and registered participants prior to the workshops.

Institutional profiles

revealed a full spectrum of engagement with IPE ranging from no IPL activities at all, to IPE teaching and learning throughout undergraduate programmes for all health professionals. Few institutions had a designated person responsible for developing and leading IPE. There appeared to be little joint, collaborative activity between academic and clinical staff in relation to IPL. Practitioners were mainly involved with programmes in a clinical educational capacity. Each host institution had its own unique aims and expectations of the workshops. All wanted more knowledge and a greater understanding of IPE, but some also wanted the workshops to enlighten key stakeholders and help gain local

30 J. of Practice Teaching \& Learning 9(3) 2009, pp.26-46. DOI: 10.1921/ 146066910X541629. @ w\&b 
agreements on approaches to working collaboratively. Others wanted ideas for future directions and developing strategies for promoting IPL. Some simply requested opportunities for networking; some hoped to be told 'how to do it' in relation to both curriculum development and facilitation of IPL in the classroom and workplace setting, and two wished for a focus on developing and supporting interprofessional clinical educators.

Individual profiles

helped identify individual learning needs. The completed profiles highlighted the potential diversity of participants attending the workshops. They came from a variety of professional backgrounds and diverse groups, indicating different levels of knowledge and understanding about IPL and differing levels of commitment to IPL. Clay et al. (1999) argue that workshop content needs to be based upon the perceived learning needs of participants as much as possible. This can be hard to achieve in large workshops with the level of diversity illustrated in the individual profiles.

Pre-workshop reflections

helped participants focus on IPL and collaboration; to identify an area which they wished further to enhance or develop in their own field of practice. They were anonymous so that any sensitive issues could be highlighted without embarrassment. Some participant reflections complemented the learning objectives set by the host institutions, but others were very different, indicating a tension between individual participant expectations and the expectations of the host institutions.

The information enabled the facilitators to determine specific areas on which to focus in relation to the attitudes, assumptions, anxieties and areas of concern which individuals expressed about facilitating IPL or interprofessional, collaborative initiatives within their local context. Additional data gathered from national and local sources during the planning process enabled an overarching, comprehensive approach to be taken in relation to content choice, learning strategies used and facilitation of the workshops; but one which encompassed an element of flexibility. 


\section{The workshops}

Three hundred and one participants attended the ten workshops, although individual location attendance varied considerably in numbers. Over thirty professions were represented. They included policy makers at regional and national level, strategic planners, senior academics, lecturers, clinical educators, senior managers, service providers, practitioners and representatives from professional bodies. At each venue, participants from other institutions attended, some by invitation, others from interest and some having travelled considerable distances. A few attended more than one workshop at more than one location and at least one person attended workshops in both countries.

Participants received a workshop resource pack in advance, containing handouts, scenarios for group discussions, examples of IPL models and approaches to IPE. Relevant national and local policy documents, articles and newsletters were made available at each workshop.

\section{Workshop format}

This focused on interactive group activities to enable participants to learn from the experience of working with and sharing experiences in diverse groups. Group experiences were interspersed with presentations on different aspects of IPE according to expressed need. The workshop plan was flexible, allowing for a degree of change in direction during the day, according to the wishes of the participants. Within each workshop plan, considerable time was allocated to allow participants to consider solutions to identified service gaps and relevant, local, work based initiatives through collaborative discourse.

Teaching tools selected used interactive learning and included role play scenarios, interprofessional e-learning exercises, case studies, group exercises and individual and group reflections. The range of strategies used enabled a sharing of views, gave permission to challenge, and permission to express negativity. IPL ground rules helped to establish an atmosphere of trust and optimism towards change noted by the facilitators at most workshops.

32 J. of Practice Teaching \& Learning 9(3) 2009, pp.26-46. DOI: 10.1921/ 146066910X541629. ( ) wEb 
Table 1

Workshop participants

\begin{tabular}{|c|c|c|c|}
\hline identified & & $\begin{array}{c}\text { Organisations/ } \\
\text { Institutions }\end{array}$ & Organisations \\
\hline $\begin{array}{l}\text { - Allied Health } \\
\text { - Assistant } \\
\text { - Applied Science } \\
\text { - Health } \\
\text { - Clinical Psychology } \\
\text { - Dental Assistant } \\
\text { - Dental Therapy } \\
\text { - Dietician } \\
\text { - Enrolled Nurse } \\
\text { - Exercise Therapist } \\
\text { - Health promotion } \\
\text { - Midwifery } \\
\text { - Medical Imaging } \\
\text { - Medicine: Hospital } \\
\text { - Medicine: General } \\
\text { - Practice } \\
\text { - Mental Health } \\
\text { - nursing / OT) } \\
\text { - Nursing, } \\
\text { - Occupational Therapy } \\
\text { - Pral Health } \\
\text { - Para medicine } \\
\text { - Pharmacy } \\
\text { - Physiotherapy } \\
\text { - Podiatry } \\
\text { - Psychotherapy } \\
\text { - Radiography } \\
\text { - Social Work } \\
\text { - Speech \& Language } \\
\text { - Technorapy } \\
\text { Sechnician } \\
\text { - Tcience } \\
\text { - }\end{array}$ & $\begin{array}{l}\text { - Health Professional; } \\
\text { - Health Educator; } \\
\text { - Health Educator / } \\
\text { - Senior Academic - } \\
\text { Research, Educator, } \\
\text { - Applied science; } \\
\text { - } \text { Manager / Funder; } \\
\text { - } \text { Project manager; } \\
\text { - Director of Services; } \\
\text { - Health Advisor; } \\
\text { - Director of Agency } \\
\text { - Academic Co- } \\
\text { - } \text { ordinator; } \\
\text { - Couff Development; } \\
\text { - Policy Advisor; } \\
\text { - Case manager. } \\
\text { - Innovation Manager }\end{array}$ & 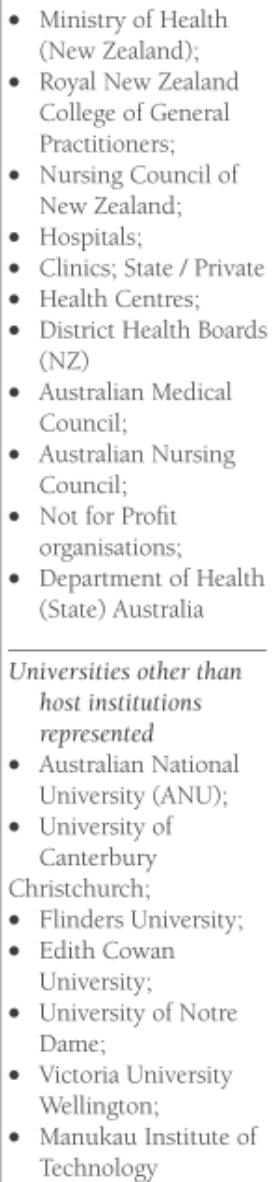 & $\begin{array}{l}\text { - Auckland University } \\
\text { of Technology; } \\
\text { - Canterbury District } \\
\text { Health Board, } \\
\text { Christchurch NZ; } \\
\text { - Canberra Institute of } \\
\text { Technology; } \\
\text { - ACT Health Canberra } \\
\text { - Curtin University of } \\
\text { Technology; } \\
\text { - Monash University } \\
\text { Melbourne; } \\
\text { - Monash University } \\
\text { Department of Rural } \\
\text { \& Indigenous Health } \\
\text { (MUDRIH) Bendigo; } \\
\text { - University of } \\
\text { - Univenash University } \\
\text { Department of } \\
\text { Rural \& Indigenous } \\
\text { Health (MUDRIH) } \\
\text { Gippsland; } \\
\text { Wellington; } \\
\text { - Univalia. } \\
\text { - } \\
\text { - }\end{array}$ \\
\hline
\end{tabular}




\section{Workshop Dialogue}

The workshop activities stimulated considerable dialogue and participants became aware of the diversity of understanding of IPL, but also of a commonality of perceptions. They were encouraged to acknowledge common frustrations but also to consider solutions. Whilst each workshop was very different from the others, over lapping themes common to all workshops emerged. Some are described below as they reflect current and ongoing issues in IPE and IPL, but also offer an insight into the learning and reflection engendered by the workshops,

\section{Evidence supporting the effectiveness of IPL}

The question of evidence of the effectiveness of IPL was raised consistently across the workshops. Some participants were themselves sceptical and others stated a need to convince colleagues still sceptical about IPL with high quality, irrefutable evidence, thereby facilitating their efforts towards change. The need for evidence of the effectiveness of IPL has been well documented (Hammick et al., 2007; Reeves et al., 2008). Nevertheless, since the World Health Organisation's (WHO) seminal report (1987), support has grown for the use of IPE to help deliver collaborative, patient centred care. Findings of systematic reviews e.g., (Barr et al., 2005; Freeth at al., 2002; Hammick et al.. 2007) have shown that an evidence base has been established and despite a belief by some that this evidence is weak and fragmentary in nature (Zwarenstein \& Reeves, 2006), it is continuing to grow, generating support of practitioners and educators in the professions and increasingly managers and policy makers across the world (Oandasan et al. (2004); Productivity Commission 2005; WHO, 2006; WHO, 2008).

\section{Language, terminology and communication}

The plethora of definitions and terminology has long caused confusion within IPE (Leathard, 1994; Barr, 2002). Discussions during each workshop highlighted examples of confusion caused by different perceptions of the same word and the communication barriers resulting from professional jargon. "Variation in language has the ability to create

34 J. of Practice Teaching \& Learning 9(3) 2009, pp.26-46. DOI: 10.1921/ 146066910X541629. @ w\&b 
exclusive professional codes of discourse that separate them from others' (Yeager, 2005). Manor-Binyamin (2007) found that professionals from different disciplines use different languages, which may hinder effective interprofessional teamwork and that understanding the different languages and key words used is the first step in improving collaboration between professionals. Participants agreed that assumptions around meaning and clarity cannot be made. There was a realisation that the various disciplines within health and social care have diverse, and sometimes conflicting, perceptions of what actually comprises effective communication.

\section{Confidentiality, trust and professional relationships}

Several workshop participants gave examples of how their health service, in the interests of patient confidentiality, prevented any direct electronic communication outside their immediate service. They described the resultant barriers to integrated care across services and agencies which their patients were then required to navigate. The apparent tension between sharing information about a patient between health and social care workers who are trying to improve and integrate their care, while maintaining a level of appropriate confidentiality was highlighted. Numerous examples, some local, others national, of patients receiving inadequate care due to a lack of trust influencing communication and information sharing between health and social care workers, were cited in all workshops. One participant made the significant observation that no patient has ever died from a breach of privacy. In each workshop, the consequences of a lack of understanding of the professional roles and responsibilities of others were discussed. Souter et al (2009) highlight the importance of role understanding and appreciation of others roles as an important prerequisite for the development of meaningful relationships and collaboration to occur.

The discussions highlighted the importance of good, trusting relationships between different professions. Trust is viewed as a prerequisite for effective team functioning (Meyerson, et al., 1996). Optimizing interprofessional care is about optimizing the people who partake in it, their relationships and valued roles, their competence and capability (Fraser \& Greenhalgh, 2001; Soubhi, 2007). 


\section{Status, power and litigation}

In all workshops, participants discussed the difference in status and power between professions and the impact this had on professional relationships, their level of collaboration and thus on the quality of care provided to patients. Many doctors saw themselves as being the ultimate accountable professional for patient care. The perceived hierarchy of professions was acknowledged and there were discussions on how the influence of professional power differentials on professional relationships, had been a significant factor in major tragedies, (e.g. Kennedy, 2001), but could also have an impact on all aspects of care.

Lively discussions took place over matching the perceived risk of treatment delivered by various disciplines to malpractice indemnity. The legal system was frequently blamed by participants for the maintenance of health professional hierarchies and there was much debate regarding responsibility, accountability and litigation.

\section{The learning process and reflection}

Underpinning the workshop planning and delivery was the firm belief that the learning process is as important as the content of the workshop and that facilitation of self-awareness and reflection should be part of that process. Clark (2009, p.214), states 'it is the process of learning in IPE that determines the success of the educational outcomes in equipping learners to work together as professionals' and 'Interprofessional education involves learning, and learning requires reflection' (p213).

The workshops offered the participants the opportunity to learn with, from and about each other and to reflect upon that learning. An individual learns from experience when s/he critically reflects upon it. Rodgers, C. (2002 p.845) writes "Reflection moves a learner from one experience into the next with a deeper understanding of its relationships with and connections to other experiences and ideas" Thus, reflection makes the continuity of learning possible and helps ensure the individual's progress. Wackerhausen (2009) argues that reflection, if carried out in the right way, can lead to longer term attitude changes, prompting action within the work context to improve the quality and

36 J. of Practice Teaching \& Learning 9(3) 2009, pp.26-46. DOI: 10.1921/ 146066910X541629. @ w\&b 
safety of patient care through collaboration between professions.

This opportunity for reflection bears fruit particularly when participants are able to move away from their own profession perspective and take on that of another profession. Workshop participants demonstrated that they were able to reflect on the limitations in their interprofessional knowledge, to recognise and acknowledge differences in professional roles and perceptions and to identify areas of their own practice where interprofessional collaboration would improve the quality of care they delivered. Workshop participants also demonstrated a high level of creative thinking and innovation when considering the challenges they faced in taking forward IPE or collaborative practice.

\section{Evaluation}

Participants were asked to complete an immediate post-workshop evaluation form and the summary of these are set out in Table 2 overleaf. The evaluation form was not rigorously tested for reliability or validity but it served to provide a participant perspective, offering helpful feedback to the facilitators. Given the very different local contexts, the diversity and numbers of those who attended the workshop and the range of individual learning expectations, the evaluations were generally very positive, although there were those who reported, not unexpectedly, that some learning needs or expectations had not been met.

However, individuals did feel that the workshops left them with a greater understanding of IPL and its underpinning principles. With awareness raised, participants were able to see why and how IPL could be included in their workplaces and service developments. Initiatives and activities reported by individuals following participation in a workshop indicate that the workshops did have some immediate and ongoing impact.

37 J. of Practice Teaching \& Learning 9(3) 2009, pp.26-46. DOI: 10.1921/ 146066910X541629. () wEb 
Helena Low and Judy Stone

Table 2

Summary of amalgamated evaluation forms from all workshops

\begin{tabular}{|c|c|c|c|}
\hline Evaluation Questions & \multicolumn{3}{|c|}{ Results and Comments } \\
\hline $\begin{array}{l}\text { 1. How helpful were the following? } \\
\text { Likert scale: } \\
5 \text { (very belpful) to } 1 \text { (not at all } \\
\text { helpful) }\end{array}$ & $\begin{array}{l}\text { a) workshop format } \\
\text { b) workshop content } \\
\text { c) learning approaches used }\end{array}$ & \multicolumn{2}{|c|}{$\begin{array}{l}\text { Mean Likert scale } \\
\text { a) } 4.15 \\
\text { b) } 3.65 \\
\text { c) } 4.05\end{array}$} \\
\hline $\begin{array}{l}\text { 2. Are there any aspects which might } \\
\text { have been approached? }\end{array}$ & $\begin{array}{l}\text { Positive feedback } \\
\text { - no improvement needed } \\
\text { - } \quad \text { good context setting }\end{array}$ & \multicolumn{2}{|c|}{$\begin{array}{l}\text { Areas for improvement } \\
\text { - seemed rushed at times } \\
\text { - discussions short } \\
\text { - more practical solutions } \\
\text { needed. }\end{array}$} \\
\hline $\begin{array}{l}\text { 3. Has your understanding of IPL } \\
\text { and its underpinning principles been } \\
\text { enhanced? }\end{array}$ & $\begin{array}{l}\text { Positive feedback } \\
\text { - yes (majotity response) } \\
\text { - consolidated } \\
\text { - } \quad \text { enhanced \& re-motivated }\end{array}$ & \multicolumn{2}{|c|}{$\begin{array}{l}\text { Areas for improvement } \\
\text { - more examples from } \\
\text { - practice would have helped } \\
\text { - need more of this locally }\end{array}$} \\
\hline $\begin{array}{l}\text { 4. What was the highlight for the } \\
\text { workshop for you? }\end{array}$ & \multicolumn{3}{|c|}{$\begin{array}{l}\text { - } \quad \text { networking and interacting } \\
\text { - the role play } \\
\text { - } \quad \text { gob \& Sarah's story (e-learning object) } \\
\text { - International / strategic context }\end{array}$} \\
\hline $\begin{array}{l}\text { 5. Did the workshop meet your } \\
\text { particular needs in relation to your } \\
\text { objectives? }\end{array}$ & Yes $=79.3 \%$ & \multicolumn{2}{|c|}{$\begin{array}{l}\text { If no-which needs were not } \\
\text { met? } \\
\text { Introduction too long } \\
\text { Limited time }\end{array}$} \\
\hline $\begin{array}{l}\text { 6. Can you identify further learning } \\
\text { needs for yourself and/or your team? }\end{array}$ & \multicolumn{3}{|c|}{$\begin{array}{l}\text { - Nore exploration of strategies needed } \\
\text { - Need to put ideas into action } \\
\text { - Yes (no additional comment) } \\
\text { - No (no additional comment) }\end{array}$} \\
\hline $\begin{array}{l}\text { 7. In relation to the format \& delivery } \\
\text { of the workshop }\end{array}$ & \multicolumn{2}{|c|}{$\begin{array}{l}\text { a) Do you feel you have had the opportunity } \\
\text { to kearn, with from and about other health } \\
\text { professionals? } \\
\text { b) Have you made any new contacts or } \\
\text { networks as a result of the workshop? } \\
\text { c) Do you have any new ideas for how to work } \\
\text { across professional, agency and service } \\
\text { boundaries? }\end{array}$} & $\begin{array}{l}\text { Mean Likert Scale } \\
\text { Yes }=88.6 \% \\
\quad \text { No }=5.2 \% \\
\text { Yes }=89 \% \\
\text { Yes }=91.4 \%\end{array}$ \\
\hline $\begin{array}{l}\text { Any additional comments you may } \\
\text { wish to make }\end{array}$ & \multicolumn{3}{|c|}{$\begin{array}{l}\text { Thank you (majority response) } \\
\text { More proof is needed }\end{array}$} \\
\hline
\end{tabular}




\section{Activities following the workshops reported as outcomes by commissioners and participants}

There had been no planned intention by the facilitators to follow up any impact or outcomes from the workshop tour - it was anticipated that this would be undertaken on an individual workshop basis by those who had commissioned them. However, it became clear that not only did individuals wish to share their activities with the facilitators, but that some initiatives crossed state and national boundaries. Information was initially volunteered by enthusiastic individuals, even before the end of the tour. This enthusiasm prompted the facilitators to contact host institutions shortly after the tour and then again after 6 months to ask informally whether the workshops had made any direct or indirect impact in relation to taking forward IPL initiatives. Two did not respond, and the data provided in Table 3 reflects only some of the activities reported by others then and up to a year since. This information is summarised and has not been subjected to any formal measurement or impartial observation.

\section{Discussion}

It is acknowledged that the initial energy and enthusiasm created by a workshop does not always translate into action and is not a measure of the effectiveness of that workshop in the longer term. Notzer \& Abramovitz (2008) found that workshops do have considerable shortterm impact but were unable to answer the question as to whether they have a long-term impact on organisational culture. Barr et al. (2005) point out that locally focused initiatives are often effective and achieve short term outcomes because they 'grow from and meet the needs of those involved'. Achievement of IPL related to positive long term outcomes is more challenging for busy clinicians to enact and more challenging to measure for research purposes.

The workshops were anecdotally reported to have had most effect within organisations (university and health services), who have a designated coordinator for IPL. This reflects findings elsewhere (Freeth, 2001).These individuals are more likely to have time, resources and authority to lead, develop and support IPL in practice and education. Prior to the workshops many host organisations did not have a

39 J. of Practice Teaching \& Learning 9(3) 2009, pp.26-46. DOI: 10.1921/ 146066910X541629. @ wE-b 
Table 3

Summary of activities reported as outcomes by local workshop commissioners and individual participants.

\section{Networking}

- An existing Health \& Social Care Interprofessional Network (HSIN) in Victoria has been strengthened and expanded into another area.

- An email based network of those with either a designated role or active in IPL in education or practice has been established across Australia and New Zealand to share experiences and resources and to provide a forum for discussion of issues directly related to the IPL role. Members are from universities and health services across Australasia

\section{New funding for IPL initiatives}

- The expansion of the HSIN described above was made possible by extra funding provided by the local Community Health service. (CHS)

- New funding by a District Health Service (DHS) to support ten local voluntary IPL facilitators in five rural regions for at least one year. These facilitators were supported to hold local meetings, share resources and organise conference abstract submissions

- A DHS was reported to commit funding to support the AIPPEN / $\mathrm{ATBH}^{1}$ interprofessional conference in Sydney 2010

\section{Collaboration between Universities}

- Two host universities collaborated on developing \& delivering state wide IPE facilitator training workshops \& worked together on a professional development event for staff.

Initiatives in Clinical Practice for improved collaborative working

- A group of workshop participants in private practice recognised, via their workshop learning, that communication and professional respect, as well as knowledge of differing roles, was lacking. Improvements in communication were planned to increase the efficiency of referrals and patient experience.

- In one CHS an IPL group was formed which is developing a Case Study of a 'typical' LCHS client and intend to involve all relevant disciplines.

\section{University and service collaboration}

- A strategy developed to embed an education session offering 'facilitation skills' on a regular basis to the health workforce, particularly targeting clinical educators. This will build on experiential learning gained at the workshop..

- The possibility of setting up two IPL clinics is being considered by one CHS in collaboration with the local university.

40 J. of Practice Teaching \& Learning 9(3) 2009, pp.26-46. DOI: 10.1921/ 146066910X541629. @ wEb 
Table 3 continued

\section{Student experience}

- A CHS organisation committed to change its policy and make students a clear priority in the organisation; clients attending the organisation will expect to see and be involved with students. Staff knowledge and skills in IPL to be developed so that individual IPL activities can be offered from July 2010 and fully integrated IPL student placements offered in 2011.

- Staff at one local teaching hospital are working on an IPE experience for speech pathology, dietetics and social work students

- The idea of piloting a ward simulation for beginning professionals (students) mooted at one workshop for clinical educators was taken forward and successfully conducted in March 2010.

IPL developments by clinical educators

- Clinical staff in one area established an IPL group. 2 IPL Forum events took place in 2009 organised by the local CHS

- A collaborative initiative to develop an IPL Toolkit which will be shared across three Community Health Services.

1. Australian Interprofessional Practice \& Education Network / All Together Better Health 5 Conference

designated IPL lead, but informal feedback indicates that a number of appointments have since been made. Those who have been appointed to these new posts have linked with others to form a dynamic supportive network which includes those in education and practice who have an interest in IPE. The network group share information and ideas and are developing innovative strategies / tools for taking forward IPL, particularly in practice.

In host institutions, the workshops appear to have had greatest impact where the institution specific learning objectives were clear and part of a planned integrated strategy for taking IPL forward. Any impact on practice and service development at local level would appear to have resulted from an enhanced understanding of the benefits of IPL and improved communication and collaboration, both within service and between service and education. Subsequent collaboration between universities and between university and service providers might have happened any way, but the workshops were reported to have provided the opportunity for initial, informal discussion, shared creative thinking and an impetus for action

41 J. of Practice Teaching \& Learning 9(3) 2009, pp.26-46. DOI: 10.1921/ 146066910X541629. (@ wEbb 
Practice learning is central to preparing competent and confident health and social care professionals, able to work collaboratively in providing complex care in a constantly changing context. All of the reported post workshop initiatives can only serve to enhance student experience and learning in practice, not just those explicitly designed for students, such as the ward simulation, but also the commitment to a student focused strategy by one CHS. Following the workshops, university and health service development of facilitation skills for IPL and ongoing support for academic and clinical facilitators was taken forward in a number of places. These local workshops reportedly built on learning from the IPL workshops. Hammick et al. (2007) emphasise that staff development is a key influence on the effectiveness of IPE.

IPE is frequently used as an effective way of enhancing practice and improving service. Examples of clinical collaboration initiatives are included in Table 3. Good collaborative working practices serve as positive role models for students and enhance the student experience in workplace settings. Good relationships and collaboration between service providers and academic institutions help ensure the quality and effectiveness of IPL and that it reflects the reality of practice.

It could be argued that many of these activities would have, or could have occurred without the workshops taking place; that any event bringing participants together with the opportunity for networking would have had similar outcomes; that the timing of the workshops was fortuitous as circumstances were such that there was already considerable interest in IPE in both Australia and New Zealand; that the post workshop activities may not be sustainable in the longer term. All these points are acknowledged. However, we also take the view that to a greater or lesser extent in each locality, these workshops created the opportunity and climate to solidify intentions and plans; that the active and interactive learning strategies used in the workshops were key factors in breaking down barriers between individuals, between professions, between universities and between education and services; and that they facilitated creative thinking and positive approaches to IPL and working. They also raised awareness and understanding of IPE and IPL beyond individual professionals and universities to national professional bodies and state policy makers.

Shortly after these workshops the launch of 'Learning and Teaching for Interprofessional Practice, Australia' (L-TIPP, Aus), supported by the Australian Learning and Teaching Council, demonstrated

42 J. of Practice Teaching \& Learning 9(3) 2009, pp.26-46. DOI: 10.1921/ 146066910X541629. (C) w\&b 
the growing critical mass of those committed to IPL. The L-TIPP document 'Interprofessional Health Education in Australia: The Way Forward' (2009) recommends that maintaining momentum with IPL in Australasia involves engaging with political agendas. If this momentum can be maintained then it may help create sustainable change within health services and higher education. The IPL workshops engaged individuals on a personal and local level, but using them as a tool to deliver IPL in a national and international context was effective and contributed to the growing momentum of IPE development in Australasia at the time.

\section{References:}

Barr, H. (2002) Interprofessional Education: Today, Yesterday and Tomorrow. London: LTSN Health Sciences and Practice. www.health.heacademy.ac.uk

Barr, H., Koppel, I., Reeves, S., Hammick, M. and Freeth, D. (2005) Effective Interprofessional Education: Argument, assumption and evidence. Oxford: Blackwell Publishing.

Centre for the Advancement of Interprofessional Education (CAIPE). (2002) Defining IPE. http://www.caipe.org.uk/about-us/defining-ipe

Clark, P. (2009a). Reflecting on reflection in interprofessional education: Implications for theory and practice Journal of Interprofessional Care; 23,3, 213-223

Clay, M.C., Hardee Lilley, S., Borre, K., Harris, J.R. (1999) Applying adult education principles to the design of a preceptor development program, Journal of Interprofessional Care, 13, 4, 405-415

Council of Australian Governments (2008) National Partnership Agreement on Hospital and Health Workforce Reform

Department of Education, Employment and Workplace Relations (2008) Review of Australian Higher Education: Final Report: Canberra. DEEWR

Fraser, S. W. and Greenhalgh, T. (2001). Complexity science: Coping with complexity: educating for capability. British Medical Journal, 323, 799-803.

Freeth, D. (2001) Sustaining Interprofessional education, Journal of Interprofessional Care, 15, 37-46

Freeth, D., Hammick, M., Koppel, I., Reeves, S. and Barr, H. (2002) A Critical Review of Evaluations of Interprofessional Education. UK Learning and Teaching Support Network (LTSN). Centre for Health Sciences and Practice.

43 J. of Practice Teaching \& Learning 9(3) 2009, pp.26-46. DOI: 10.1921/ 146066910X541629. @ wE-b 
Occasional Paper: 2.

Fronek, P., Kendall, M., Ungerer, G., Malt, J., Euregarde, G., and Geraghty, T., (2009). Towards healthy professional-client relationships: The value of an interprofessional training course. Journal of Interprofessional Care, 23, $1,16-29$

Hammick, M., Freeth, D., Koppel, I., Reeves, S. and Barr, H. (2007) A best evidence systematic review of interprofessional education: BEME Guide no. 9, Medical Teacher, 29, 8, 735-751

Holland K (2002) Interprofessional education and practice: the role of the teacher/facilitator. Nurse Education in Practice, 2, 221-222

Howkins, E. and Bray, J. (Eds) (2008) Preparing for Interprofessional Teaching: Theory and practice. Abingdon: Radcliffe

Kennedy. I, (2001) The Report of the Public Enquiry into Children's Heart Surgery at the Bristol Royal Infirmary 1984-1995, London: The Stationery Office

Learning and Teaching for Interprofessional Practice, Australia (L-TIPP) (2009) Interprofessional Health Education in Australia: The way forward. A project funded by the Australian Learning and Teaching Council. Surrey Hills, NSW: Australian Learning and Teaching Council

Leathard, A. (1994) Going Interprofessional. London: Routledge

Low, H. and Stone, J. (2008) Interprofessional Working: Distance no barrier. CAIPE Bulletin July 2008, 13-16

Low, H, (1998) Developing and Enhancing Skills to Facilitate Teaching in Interprofessional Education: Report of the joint national workshop, London: ENB, CCETSW, COT

Manor-Binyamini, I. (2007) Meaning of language differences between doctors and educators in a collaborative discourse Journal of Interprofessional Care, $21,1,31-43$

Meads, G. and Ashcroft, J. (Eds) (2005) The Case for Interprofessional Collaboration in Health and Social Care. Oxford: Blackwell Publishing

Meyerson, D., Weick, K., and Kramer, M. (1996) Swift Trust and Temporary Groups in M. Kramer and M. Tyler (Eds) Trust in Organisations: Frontiers of theory and research. Thousand Oaks, CA: Sage Publications

New Zealand Health Workforce Advisory Committee Report (2003) The New Zealand Health Workforce Future Directions-Recommendations to the Minister of Health. Wellington: Health Workforce Advisory Committee. http://www.hwac.govt.nz/publications/HWACfuturedirections03.pdf

New Zealand Workforce Taskforce (2008) Working Together for Better Primary Health Care, Overcoming barriers to workforce change and innovation. Report to the Minister of Health from the Workforce Taskforce.

44 J. of Practice Teaching \& Learning 9(3) 2009, pp.26-46. DOI: 10.1921/ 146066910X541629. @ w\&b 
http://www.waikatodhb.govt.nz/file/fileid/10361

Notzer, N., Abrimovitz, R. (2008) Can brief workshops improve clinical instruction? Medical Education, 42, 152-156

Oandasan, I., D’Amour, D., Zwarenstein M., Barker K., Purden M., Beaulieu M., Reeves S., Nasmith L., Bosco, C., Ginsburg L., Tregunno, D. (2004) Interdisciplinary Education for Collaborative, Patient-centred Practice. Health Canada: Ottawa

Poole, G., Egan, J.P., and Lqbal (2009) Innovation in collaborative health research training: The role of active learning. Journal of Interprofessional Care, 2, 2, 148-155

Productivity Commission (2005) Australia's Health Workforce. Canberra: Productivity Commission,

http://www.pc.gov.au/__data/assets/pdf_file/0003/9480/healthworkforce.pdf

Reeves, S., Goldman, J, Oandasan, I. (2007), Interprofessional Education in Health Care Settings Journal of Allied Health, 36, 4

Reeves, S., Zwarenstein, M., Goldman, J., Barr, H., Freeth, D., Hammick, M., and Koppel, I. (2008) Interprofessional Education: Effects on professional practice and health care outcomes, Cochrane Database of Systematic Reviews, Issue 1. Art. No: CD002213. DOI: 10.1002/14651858.CD002213 pub 2.

Rodgers, C.(2002) Defining Reflection: Another look at John Dewy and Reflective Thinking. Teachers College Record, 104, 4, 842- 866

Singh, S.P., Baxter, H,. Standen, P and Duggan, C. (1998) Changing the Attitudes of 'Tomorrow's Doctors' towards Mental Illness and Psychiatry: A comparison of two teaching methods, Oxford: Blackwell Science

Soubhi, H. (2007) The greatest challenge of interprofessional education. Network Toward Unity for Health, , no 02.

www.the-networktufh.org/publications_resources/newsletterdetail

Soubhi, H., Colet, N., Gilbert, J., Lebel, P., Thiverge, R., Hudon, C., and Fortin, M. (2009) Interprofessional learning in the trenches: Fostering collective capability, Journal of Interprofessional Care, 23, 1, 52-57

Suter, E., Arndt, J., Arthur, N., Parboosingh, J., Taylor, E. and Deutschlander, S. (2009) Role understanding and effective communication as core competencies for collaborative practice. Journal of Interprofessional Care, 23, 1, 41-51

Stone, J. (2009) Interprofessional Collaborative Practice (IPCP) Definitions and Terminology: Attempting to speak the same language. ACT Health. Canberra

World Health Organisation (1987) Learning Together to Work Together for Health, Technical Report No. 769, World Health Organisation: Geneva

World Health Organization (2006) Working Together for Health. The World

45 J. of Practice Teaching \& Learning 9(3) 2009, pp.26-46. DOI: 10.1921/ 146066910X541629. @ wEb 
Health Report 2006, Geneva: WHO

World Health Organization (2008) Primary Health Care: Now more than ever. The World Health Report 2008, Geneva: WHO

Wackerhausen, S (2009) Collaboration, professional identity and reflection across boundaries Journal of Interprofessional Care, 23, 5, 455-473

Zwarenstein, M. and Reeves, S. (2006) Knowledge translation and interprofessional collaboration: where the rubber of evidence based care hits the road of teamwork. Journal of Continuing Education in the Health Professions, $26,46-54$ 